\title{
Item position effects in listening but not in reading in the European Survey of Language Competence
}

\author{
Andrés Christiansen \\ Centre for Educational Effectiveness and Evaluation \\ Katholieke Universiteit Leuven \\ andres.christiansen@kuleuven.be
}

\section{Rianne Janssen}

Centre for Educational Effectiveness and Evaluation

Katholieke Universiteit Leuven

rianne.janssen@kuleuven.be

\begin{abstract}
In contrast with the assumptions made in standard measurement models used in large-scale assessments, students' performance may change during the test administration. This change can be modeled as a function of item position in case of a test booklet design with item-order manipulations. The present study used an explanatory item response theory (IRT) framework to analyze item position effects in the 2012 European Survey on Language Competences. Consistent item position effects were found for listening but not for reading. More specifically, for a large subset of items, item difficulty decreased along with item position; which is known as a "practice effect". The effect was found across all tested languages, although the effect sizes varied across items, test levels and countries.
\end{abstract}

Keywords: item position effects, multilevel IRT, large-scale assessments.

\section{Introduction}

International large-scale assessments, such as the Programme for International Student Assessment (PISA) or the Trends in International Mathematics and Science Study (TIMSS), make use of models from item response theory (IRT) to transform each student's responses on a subset of the test items into a single scale score. The same measurement scale is assumed to hold across test booklets within and across years of administration. Hence, the correct modeling of the response data is a prerequisite for the validity of the comparisons of countries and students. It is known that in standardized assessments, the performance of test takers can be influenced by the position of the items in the test. In such cases, one may say that 'measuring changes the 
measure' (Knowles, 1988, p. 312). If such item position effects are not included in the measurement model, this may lead to distorted item parameter estimates (see e.g., Oshima, 1994; Wise, 1986) and may be a possible threat to IRT's local independence assumption (Hartig \& Buchholz, 2012). In the present study, it will be investigated whether item position effects are present in a large-scale European assessment on foreign language comprehension of 15-yearold students, and if they vary across educational systems. In the following, previous studies on the effect of item position on psychometric item properties are summarized first. Afterwards, the research design and modeling approach of the present study are discussed.

\section{Item position effects on psychometric item characteristics}

Item position effects have been studied both in educational measurement and personality assessment. Effects have been found on item difficulty and item discrimination, as will be discussed subsequently.

Item difficulty. The question of whether item position affects the trait that is measured has a long history. For example, Guertin (1954) showed that item order yielded a significant difference in performance on the arithmetic subtest of the Wechsler-Bellevue. As another example, Hambleton and Traub (1974) investigated the effects of item order on test performance and stress. They found for a mathematics test that the mean number of correct answers was significantly lower for questions arranged in the difficult-to-easy order than for the reverse order. The difficult-to-easy order also increased heart rate more than the easy-to-difficult order. In general, two opposite effects of item position on item difficulty have been observed (Bejar, 1985; Kingston \& Dorans, 1982): item difficulty may either increase or decrease towards the end of the test. The decreased and increased performance of students as functions of item position are called a fatigue and practice effect, respectively.

Fatigue effects have been commonly reported (see e.g., J. Davis \& Ferdous, 2005; Hohensinn et al., 2008; Meyers, Miller, \& Way, 2009; Whitely \& Dawis, 1976; Yen, 1980). Moreover, they have been consistently found across all participating regions in the PISA assessments of 2006, 2009, and 2012 (Debeer, Buchholz, Hartig, \& Janssen, 2014; Debeer \& Janssen, 2013; Hartig \& Buchholz, 2012; Wu, Debeer, Buchholz, Hartig, \& Janssen, 2019). Fatigue effects have been related to changes in student engagement during the test, especially in low-stakes assessments (e.g., Cosgrove \& Cartwright, 2014). Wu et al. (2019) found that girls were able 
to keep up their performances better than boys and that students who reported to enjoy reading showed less decline in performance on the PISA 2009 reading assessment. Nagy, Nagengast, Becker, Rose, and Frey (2018) also showed that individual differences in effort and fatigue were related to decoding speed and reading enjoyment.

Practice effects have not been found frequently. Kingston and Dorans (1984) reported practice effects in items involving the analysis of explanations and logical diagrams in the Graduate Record Examination in 1980. According to these authors, items became easier to deal with once the examinees were familiar with an item type and fully understood (see also Swinton, Wild, \& Wallmark, 1983). Practice effects can also be identified as learning during testing (Verguts \& De Boeck, 2000). Substantive individual differences in learning effects were found within tests measuring fluid intelligence, such as the Advanced Progressive Matrices (APM) (Ren, Wang, Altmeyer, \& Schweizer, 2014; Schweizer, Schreiner, \& Gold, 2009; Schweizer, Troche, \& Rammsayer, 2011).

Item discrimination. In personality assessment, several studies (see e.g., Hamilton \& Shuminsky, 1990; Knowles \& Byers, 1996) have reported a positive correlation between item position and item discrimination as measured by the item-test correlation. The explanation of the effect is given with reference to the underlying response process: throughout responding to self-report measures respondents better comprehend the inquiry and understand the common meaning of items on the one hand (Knowles \& Byers, 1996) and show an increased activation of the self-schema on the other hand (Knowles, 1988). Increased consistency of test responses was also found in social surveys when a questionnaire is administered repeatedly to the same respondents within short-time intervals (Jagodzinski, Kühnel, \& Schmidt, 1987). This phenomenon is called the 'Socratic effect' (McGuire, 1960) after the Greek philosopher Socrates whose method was to ask an individual a series of subsequent questions to encourage fundamental insight into the issue at hand. According to Jagodzinski et al. (1987), the increased consistency across tests is due to the fact that the item content becomes more salient so that respondents understand the meaning of items better and recognize similarities among the different items. Steinberg (1994) used IRT models to investigate the reliability shift in personality measures and found the changes in item discrimination were related to more specific itemcontext effects due to both the items' content and their serial position.

In educational measurement, on the other hand, a decrease in the correlation of the end-of- 
test items with the latent trait can be expected in some situations. In case (some) test takers do not have sufficient time to attempt every item in the test within the allocated time, test takers may switch to a pure guessing strategy (see e.g., Yamamoto \& Everson, 1997). Alternative IRT models have been proposed to model the response strategy switches of examinees towards the end of the test (Bolt, Cohen, \& Wollack, 2002; Goegebeur, De Boeck, Wollack, \& Cohen, 2008).

\section{The present study}

Data. Studies on item position effects in large-scale assessments mostly focused on national assessments (e.g., Albano, Cai, Lease, \& McConnel, 2019; Hohensinn, Kubinger, Reif, Schleicher, \& Khorramdel, 2011), a national sample of an international assessment (e.g., Nagy, Nagengast, Frey, Becker, \& Rose, 2018), or modeled the results of an international assessment for each country separately (e.g., Debeer et al., 2014; Hartig \& Buchholz, 2012; Wu et al., 2019). In the present study, we will show that item position effects can also be estimated in a single model in which separate position effects for each region can be estimated.

More specifically, data from the European Survey on Language Competences (ESLC), conducted in 2011, were analyzed. The ESLC tested the reading, listening, and writing competence in the different second languages (or shortly L2 languages) taught to 15-year-old students across Europe. For reading and listening, a partially rotated booklet design was used. This allows investigating item position effects for two different language competences (reading and listening) across different assessed languages (i.e., English, Spanish, French, German, and Italian). In a second step, it is explored whether these item position effects for each language differ across regions.

Modeling approach. Debeer and Janssen (2013) showed that when a test is administered with a rotated booklet design, the effect of item difficulty and item position can be disentangled. More specifically, they argued that item position effects can be considered as an instance of differential item function (DIF), where groups of test takers are distinguished based on the test booklet they respond. As item position should not play a role in the estimation of the ability of the test takers (like gender in DIF research), it is taken into account by adapting the item parameters for the different test booklets. Hence, when an item is administered at the beginning of the test, the item is modeled as being in the reference group (i.e., without an item 
position parameter). However, when the same item is administered in a different position in another test booklet, a position (or DIF) parameter is added. This parameter pertains only to those booklets where the item is in that position. The chosen parameterization has the advantage that items across different positions are modeled by two parameters: their common item difficulty and the effect of item position. It can be tested whether and what kind of item position effect is present.

Debeer and Janssen (2013) also showed that a linear trend can summarize these different DIF-parameters across item positions. This can only be done in situations where there is a sufficiently informative test administration design where item position is systematically varied (like in a Latin square design). If this is not the case, the effect of item position can be investigated only for the different positions available in the test administration design, as in the current application. Debeer and Janssen (2013) also proposed models to investigate the effects of item position both on item difficulty and item discrimination. However, the present study will only focus on the effects on item difficulty given that item discrimination was not included in the original IRT modeling of the international data of the test at hand.

As other studies have shown, it is expected to find item position effects in reading. However, there are no studies concerning international listening assessments to base expectations upon. As other studies suggest, with respect to the differences between countries, we expect to find similar item position effects between educational systems.

\section{Method}

\section{Data}

The ESLC was administered in 2011 to 16 European educational systems (see Table 1). It tested the proficiency in the European most widely taught L2 languages for ISCED2 and ISCED3 students (European Commission, 2012a). More specifically, ESLC tested the proficiency in listening, reading, and writing at levels A1 to B2 of the Common European Framework of Reference for Languages (CEFR) in English, French, German, Italian and Spanish. Regions were allowed to choose between a paper-based and computer-based administration. The current study estimated item position effects for listening and reading in English, French, German and Spanish, comprising a total of 43797 students across regions and languages (European Commission, 2012b). Table 1 shows the distribution of students per region and tested language. 
The ESLC cognitive data are publicly available and was obtained through a data request to the European Commission. While in this study, missing responses were omitted, additional analyses using incorrect answering substitution did not affect the found item position effects.

Table 1

Number of participating students per region and tested language

\begin{tabular}{lccccc}
\hline \multirow{2}{*}{ Region } & Test & \multicolumn{4}{c}{ Tested language } \\
\cline { 3 - 6 } & Mode & English & French & German & Spanish \\
\hline East Belgium & Paper & 720 & 959 & & \\
Flanders (Belgium) & Computer & 1591 & 1661 & & \\
Wallonia (Belgium) & Computer & 1501 & & 1209 & \\
Bulgaria & Paper & 1626 & & 1664 & \\
Croatia & Paper & 1651 & & 1693 & \\
Estonia & Paper & 1660 & & 1380 & \multirow{2}{*}{1575} \\
France & Paper & 1509 & & & \\
Greece & Paper & 1594 & 1378 & & \\
Malta & Paper & 1197 & & & \\
Netherlands & Computer & 1441 & & 1428 & \\
Poland & Paper & 1764 & & 1560 & \\
Portugal & Computer & 1603 & 1708 & & \\
Slovenia & Paper & 1596 & & 1642 & \\
Spain & Paper & 1734 & 1746 & & \multirow{2}{*}{1428} \\
Sweden & Paper & 1579 & & & \\
\hline \multicolumn{2}{l}{ The data of England were not available for this study. } &
\end{tabular}

\section{Design}

The ESLC assessment was organized in three different test levels that assessed items of two adjacent CEFR levels (see Figure 1). In most regions, students took a preliminary test or routing test, which provided information about their general performance level that was consequently used to assign them to one of three test levels. In a few regions a teacher questionnaire containing can-do statements about their students or exam results were used to assign students to the test levels (European Commission, 2012b). 


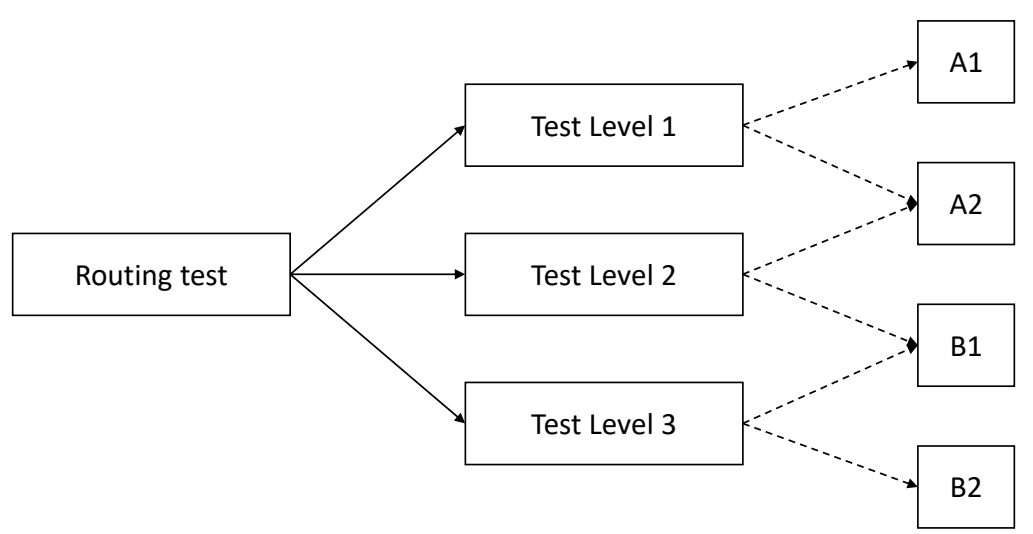

Figure 1. ESLC test level allocation and CEFR levels of the assigned booklets for reading and listening

For reading and listening each student within each test level was assigned randomly to a booklet, from a total of 7 booklets for listening, and 18 booklets for reading. Each booklet contained between 3 and 5 testlets, and every testlet included between 4 and 10 items. These items consisted of a series of selected response types refering to same listening or reading subject (European Commission, 2012b).

Testlets could be presented in different positions within and between test levels. Tables 2 and 3 show the position in which each testlet was presented within all booklets for the listening and reading tests. All tested languages followed the same design. In the case of listening, it is not possible to estimate item position effects for Test Level 1 because all testlets are presented in the same order for all students. Nevertheless, it is possible to estimate position effects for Test Levels 2 and 3. For example, Testlet 4 is presented only in Position 4 in Test Level 1; but also it can be presented in Position 1, 2 or 3 in Test Level 2. Hence, a position effect can be estimated comparing the difficulty of Testlet 4 for Positions 2 and 3 with the difficulty of the testlet items for Position 1. For reading, item position effects can be estimated for all test levels. 
Table 2

Test administration design for listening

\begin{tabular}{|c|c|c|c|c|c|c|c|c|c|c|c|c|c|c|c|c|}
\hline \multirow{2}{*}{$\begin{array}{l}\text { Testlet } \\
\text { number }\end{array}$} & \multirow{2}{*}{ CEFR } & Level & \multicolumn{5}{|c|}{1} & \multicolumn{5}{|c|}{2} & \multicolumn{4}{|c|}{3} \\
\hline & & Position & P1 & P2 & P3 & P4 & P5 & P1 & $\mathrm{P} 2$ & P3 & P4 & P5 & P1 & P2 & P3 & P4 \\
\hline 1 & A1 & & $\mathrm{A}_{l}$ & & & & & & & & & & & & & \\
\hline 2 & A1 & & & $\mathrm{A}_{l}$ & & & & & & & & & & & & \\
\hline 3 & A2 & & & & $\mathrm{B}_{l}$ & & & $\mathrm{C}_{l}$ & $\mathrm{D}_{l}$ & $\mathrm{E}_{l}$ & & & & & & \\
\hline 4 & A 2 & & & & & $\mathrm{~B}_{l}$ & & $\mathrm{C}_{l}$ & $\mathrm{D}_{l}$ & $\mathrm{E}_{l}$ & & & & & & \\
\hline 5 & A2 & & & & & & $\mathrm{B}_{l}$ & $\mathrm{C}_{l}$ & $\mathrm{D}_{l}$ & $\mathrm{E}_{l}$ & & & & & & \\
\hline 6 & B1 & & & & & & & & & & & $\mathrm{G}_{l}$ & $\mathrm{H}_{l}$ & $\mathrm{I}_{l}$ & & \\
\hline 7 & B1 & & & & & & & & & & $\mathrm{F}_{l}$ & $\mathrm{G}_{l}$ & $\mathrm{H}_{l}$ & $\mathrm{I}_{l}$ & & \\
\hline 8 & B1 & & & & & & & & & & $\mathrm{F}_{l}$ & $\mathrm{G}_{l}$ & $\mathrm{H}_{l}$ & $\mathrm{I}_{l}$ & & \\
\hline 9 & B2 & & & & & & & & & & & & & & $\mathrm{J}_{l}$ & $\mathrm{~K}_{l}$ \\
\hline 10 & B2 & & & & & & & & & & & & & & & $\mathrm{J}_{l}$ \\
\hline 11 & B2 & & & & & & & & & & & & & & $\mathrm{J}_{l}$ & \\
\hline
\end{tabular}

Letters $\mathrm{A}_{l}$ to $\mathrm{K}_{l}$ represent the different positions in which the items of different CEFR levels were presented in each test level.

Table 3

Test administration design for reading

\begin{tabular}{|c|c|c|c|c|c|c|c|c|c|}
\hline \multirow{2}{*}{$\begin{array}{l}\text { Testlet } \\
\text { number }\end{array}$} & \multirow{2}{*}{ CEFR } & Level & \multicolumn{2}{|c|}{1} & \multicolumn{2}{|c|}{2} & \multicolumn{3}{|c|}{3} \\
\hline & & Position & $\begin{array}{ll}\text { P1 } & \text { P2 }\end{array}$ & $\begin{array}{ll}\text { P3 } & \text { P4 }\end{array}$ & $\begin{array}{|ll|}\text { P1 } & \text { P2 }\end{array}$ & $\begin{array}{ll}\text { P3 } & \text { P4 }\end{array}$ & P1 & $\mathrm{P} 2$ & $\mathrm{P} 3$ \\
\hline 1 & A1 & & $\mathrm{A}_{r} \quad \mathrm{~B}_{r}$ & & & & & & \\
\hline 2 & A1 & & $\mathrm{A}_{r} \quad \mathrm{~B}_{r}$ & & & & & & \\
\hline 3 & A1 & & $\mathrm{A}_{r} \quad \mathrm{~B}_{r}$ & & & & & & \\
\hline 4 & A 2 & & & $\mathrm{C}_{r} \quad \mathrm{D}_{r}$ & $\mathrm{E}_{r} \quad \mathrm{~F}_{r}$ & & & & \\
\hline 5 & A 2 & & & $\begin{array}{ll}\mathrm{C}_{r} & \mathrm{D}_{r}\end{array}$ & $\mathrm{E}_{r} \quad \mathrm{~F}_{r}$ & & & & \\
\hline 6 & A 2 & & & $\mathrm{C}_{r} \quad \mathrm{D}_{r}$ & $\mathrm{E}_{r} \quad \mathrm{~F}_{r}$ & & & & \\
\hline 7 & A2 & & & $\begin{array}{ll}\mathrm{C}_{r} & \mathrm{D}_{r}\end{array}$ & $\mathrm{E}_{r} \quad \mathrm{~F}_{r}$ & & & & \\
\hline 8 & B1 & & & & & $\begin{array}{ll}\mathrm{G}_{r} & \mathrm{H}_{r}\end{array}$ & $\mathrm{I}_{r}$ & $\mathbf{J}_{r}$ & \\
\hline 9 & B1 & & & & & $\begin{array}{ll}\mathrm{G}_{r} & \mathrm{H}_{r}\end{array}$ & $\mathrm{I}_{r}$ & & \\
\hline 10 & B1 & & & & & $\begin{array}{ll}\mathrm{G}_{r} & \mathrm{H}_{r}\end{array}$ & & $\mathrm{I}_{r}$ & \\
\hline 11 & B2 & & & & & & $\mathrm{K}_{r}$ & $\mathrm{~L}_{r}$ & $\mathbf{M}_{r}$ \\
\hline 12 & B2 & & & & & & $\mathrm{K}_{r}$ & $\mathrm{~L}_{r}$ & $\mathbf{M}_{r}$ \\
\hline 13 & B2 & & & & & & $\mathrm{K}_{r}$ & $\mathrm{~L}_{r}$ & $\mathbf{M}_{r}$ \\
\hline
\end{tabular}

Letters $\mathrm{A}_{r}$ to $\mathrm{M}_{r}$ represent the different positions in which the items of different CEFR levels were presented in each test level.

Item position modeling Item position effects were estimated within the framework of descriptive and explanatory IRT models (De Boeck \& Wilson, 2004). An IRT model examinees' probability of correctly answering an item on the basis of their ability and the item's difficulty. 
Equation (1) presents the basic IRT model (also called the Rasch model), which is extensively explained in De Boeck and Wilson (2004) as well as further extensions of this model. Note that instead of modeling the success probability, the logit of a correct response is used as the dependent variable in Equation (1) as this allows to write the IRT model on the right hand side using a simple linear equation.

$$
\operatorname{logit}\left[Y_{c p i}=1\right]=\Theta_{c p}-B_{i}
$$

$Y_{c p i}$ represent the response of student $p$ from region $c$ to item $i, \Theta_{c p}$ the ability of student $p$ from region $c$, and $B_{i}$ the difficulty of item $i$. Explanatory IRT models further decompose examinees' ability and items' difficulty on the basis of characteristics of examinees and items. In our application, the explanatory variables for the examinees were region effects (allowing to investigate differences in mean ability across regions) and test level effects (allowing to investigate the main effect of test level on ability). The latter effects have to be added to the model as the students were not randomly assigned to the test level but based on the routing test. Equation (2) presents the model formulation for explaining differences in ability among students:

$$
\Theta_{c p}=\varepsilon_{p}+\omega_{c}+\sum_{t=2}^{T} 1_{t c p} \lambda_{t c}
$$

in which $\omega_{c}$ is the mean ability of region $c, 1_{t c p}$ is an indicator function of student $p$ from region $c$ being tested in at least test level $t$, and $\lambda_{t c}$ is the corresponding cumulative effect of test level t. An item's position is an example of an item characteristic and may therefore be used as a variable that may partially explain differences in difficulty among the items. The effect of item position is modeled using the parameter $\delta$. Equation (3) is an adapted version of the model for item position effects of Debeer and Janssen (2013) to decompose item difficulty taking into account the item position of an item for a given CEFR level and test level:

$$
B_{i}=\beta_{i 0}+\sum_{t=L 1}^{T} \sum_{r=A 1}^{R} \sum_{k=2}^{K} 1_{r_{k} i}^{t} \delta_{r_{k}}^{t}
$$

where $\beta_{i 0}$ is the item difficulty of the reference situation, $1_{r_{k} i}^{t}$ is an indicator function of item $i$ being presented in test level $t$, belonging to CEFR level $r$ and being in position $k$, and $\delta_{r_{k}}^{t}$ is the position effect of item $i$ from CEFR level $r$, being presented in position $k$ in test level $t$. Not all combinations of test level, CEFR and position are possible, therefore, the number of effects is 
different between listening and reading assessments. Table 4 and 5 show the general formulas for ability and difficulty according to the different cells of the test administration design (see Tables 2 and 3).

Table 4

Ability and difficulty formulas for listening

\begin{tabular}{cccll}
\hline Test Level & CEFR level & Cell & \multicolumn{1}{c}{ Ability } & Difficulty \\
\hline 1 & $\mathrm{~A} 1$ & $\mathrm{~A}_{l}$ & $\varepsilon_{p}+\omega_{c}$ & $\beta_{i 0}$ \\
& $\mathrm{~A} 2$ & $\mathrm{~B}_{l}$ & $\varepsilon_{p}+\omega_{c}$ & $\beta_{i 0}$ \\
2 & & $\mathrm{C}_{l}$ & $\varepsilon_{p}+\omega_{c}+\lambda_{2 c}$ & $\beta_{i 0}$ \\
& & $\mathrm{D}_{l}$ & $\varepsilon_{p}+\omega_{c}+\lambda_{2 c}$ & $\beta_{i 0}+\delta_{A 2_{2}}^{L 2}$ \\
& & $\mathrm{E}_{l}$ & $\varepsilon_{p}+\omega_{c}+\lambda_{2 c}$ & $\beta_{i 0}+\delta_{A 2_{3}}^{L 2}$ \\
& $\mathrm{~B} 1$ & $\mathrm{~F}_{l}$ & $\varepsilon_{p}+\omega_{c}+\lambda_{2 c}$ & $\beta_{i 0}$ \\
3 & & $\mathrm{G}_{l}$ & $\varepsilon_{p}+\omega_{c}+\lambda_{2 c}$ & $\beta_{i 0}+\delta_{B 1_{5}}^{L 2}$ \\
& & $\mathrm{H}_{l}$ & $\varepsilon_{p}+\omega_{c}+\lambda_{2 c}+\lambda_{3 c}$ & $\beta_{i 0}$ \\
& & $\mathrm{I}_{l}$ & $\varepsilon_{p}+\omega_{c}+\lambda_{2 c}+\lambda_{3 c}$ & $\beta_{i 0}+\delta_{B 1_{2}}^{L 3}$ \\
& $\mathrm{~B} 2$ & $\mathrm{~J}_{l}$ & $\varepsilon_{p}+\omega_{c}+\lambda_{2 c}+\lambda_{3 c}$ & $\beta_{i 0}$ \\
& & $\mathrm{~K}_{l}$ & $\varepsilon_{p}+\omega_{c}+\lambda_{2 c}+\lambda_{3 c}$ & $\beta_{i 0}+\delta_{B 2_{4}}^{L 3}$ \\
\hline
\end{tabular}

Table 5

Ability and difficulty formulas for reading

\begin{tabular}{cccll}
\hline Test Level & CEFR level & Cell & \multicolumn{1}{c}{ Ability } & Difficulty \\
\hline 1 & $\mathrm{~A} 1$ & $\mathrm{~A}_{r}$ & $\varepsilon_{p}+\omega_{c}$ & $\beta_{i 0}$ \\
& & $\mathrm{~B}_{r}$ & $\varepsilon_{p}+\omega_{c}$ & $\beta_{i 0}+\delta_{A 1_{2}}^{L 1}$ \\
& $\mathrm{~A} 2$ & $\mathrm{C}_{r}$ & $\varepsilon_{p}+\omega_{c}$ & $\beta_{i 0}$ \\
& & $\mathrm{D}_{r}$ & $\varepsilon_{p}+\omega_{c}$ & $\beta_{i 0}+\delta_{A 2_{4}}^{L 1}$ \\
2 & $\mathrm{~A} 2$ & $\mathrm{E}_{r}$ & $\varepsilon_{p}+\omega_{c}+\lambda_{2 c}$ & $\beta_{i 0}$ \\
& & $\mathrm{~F}_{r}$ & $\varepsilon_{p}+\omega_{c}+\lambda_{2 c}$ & $\beta_{i 0}+\delta_{A 2_{2}}^{L 2}$ \\
& $\mathrm{~B} 1$ & $\mathrm{G}_{r}$ & $\varepsilon_{p}+\omega_{c}+\lambda_{2 c}$ & $\beta_{i 0}$ \\
& & $\mathrm{H}_{r}$ & $\varepsilon_{p}+\omega_{c}+\lambda_{2 c}$ & $\beta_{i 0}+\delta_{B 1_{4}}^{L 2}$ \\
& $\mathrm{~B} 1$ & $\mathrm{I}_{r}$ & $\varepsilon_{p}+\omega_{c}+\lambda_{2 c}+\lambda_{3 c}$ & $\beta_{i 0}$ \\
& & $\mathrm{~J}_{r}$ & $\varepsilon_{p}+\omega_{c}+\lambda_{2 c}+\lambda_{3 c}$ & $\beta_{i 0}+\delta_{B 1_{2}}^{L 3}$ \\
& $\mathrm{~B} 2$ & $\mathrm{~K}_{r}$ & $\varepsilon_{p}+\omega_{c}+\lambda_{2 c}+\lambda_{3 c}$ & $\beta_{i 0}$ \\
& & $\mathrm{~L}_{r}$ & $\varepsilon_{p}+\omega_{c}+\lambda_{2 c}+\lambda_{3 c}$ & $\beta_{i 0}+\delta_{B 2_{2}}^{L 3}$ \\
& & $\mathrm{M}_{r}$ & $\varepsilon_{p}+\omega_{c}+\lambda_{2 c}+\lambda_{3 c}$ & $\beta_{i 0}+\delta_{B 2_{3}}^{L 3}$ \\
\hline
\end{tabular}

The combined model of (2) and (3) will be able to show if there are item position effects within the ESLC assessment for reading and listening. In a second step, for comparing item position effects between regions, dummy variables were introduced for every combination of $\delta$ and region, in that way, the position effect for each region within a CEFR level and a test level is estimated separately. 
Procedure The data were cleaned, transformed and analyzed using the programming language R (R Core Team, 2019). The original data provided by the European Commission were transformed into the long format proposed by De Boeck et al. (2011) in order to estimate the general model and the region distinctive model using the glmer function of package lme 4 (Bates, Mächler, Bolker, \& Walker, 2015).

Procedure The data were cleaned, transformed and analyzed using the programming language R (R Core Team, 2019). The original data provided by the European Commission were transformed into the long format proposed by De Boeck et al. (2011) in order to estimate the general model and the region distinctive model using the glmer function of package lme 4 (Bates et al., 2015).

\section{Results}

\section{Descriptive statistics}

The percentage of correct responses was first calculated for every combination of position and testlet, showing an overview of possible position effects. Tables 6 and 7 show respectively the percentage of correct responses of testlets with different positions for listening and reading.

Table 6

Percentage of correct responses of each testlet per CEFR level and position - listening

\begin{tabular}{|c|c|c|c|c|c|c|c|c|c|}
\hline \multirow{3}{*}{ Language } & \multicolumn{4}{|c|}{ A2 } & \multicolumn{5}{|c|}{ B1 } \\
\hline & \multirow{2}{*}{ Testlet } & \multicolumn{3}{|c|}{ Test Level 2} & \multirow{2}{*}{ Testlet } & \multicolumn{2}{|c|}{ Test Level 2} & \multicolumn{2}{|c|}{ Test Level 3} \\
\hline & & P1 & P2 & P3 & & P4 & P5 & P1 & P2 \\
\hline \multirow[t]{3}{*}{ English } & 3 & 69 & 75 & 76 & 6 & 65 & 63 & 90 & 90 \\
\hline & 4 & 82 & 84 & 84 & 7 & 56 & 58 & 75 & 80 \\
\hline & 5 & 67 & 66 & 69 & 8 & 54 & 53 & 76 & 77 \\
\hline \multirow[t]{3}{*}{ French } & 3 & 57 & 56 & 58 & 6 & 53 & 52 & 66 & 67 \\
\hline & 4 & 62 & 66 & 68 & 7 & 38 & 39 & 49 & 50 \\
\hline & 5 & 56 & 56 & 57 & 8 & 46 & 46 & 53 & 55 \\
\hline \multirow[t]{3}{*}{ German } & 3 & 78 & 80 & 83 & 6 & 44 & 42 & 59 & 64 \\
\hline & 4 & 59 & 62 & 62 & 7 & 40 & 37 & 53 & 52 \\
\hline & 5 & 55 & 57 & 57 & 8 & 54 & 55 & 68 & 66 \\
\hline \multirow[t]{3}{*}{ Spanish } & 3 & 56 & 64 & 66 & 6 & 34 & 37 & 42 & 41 \\
\hline & 4 & 55 & 55 & 53 & 7 & 26 & 30 & 31 & 36 \\
\hline & 5 & 58 & 58 & 60 & 8 & 48 & 43 & 49 & 49 \\
\hline
\end{tabular}


Table 7

Percentage of correct responses per CEFR level and position - reading

\begin{tabular}{|c|c|c|c|c|c|c|c|c|c|c|c|c|c|c|c|c|}
\hline \multirow{3}{*}{ Language } & \multicolumn{3}{|c|}{$\mathrm{A} 1$} & \multicolumn{5}{|c|}{$\mathrm{A} 2$} & \multicolumn{5}{|c|}{$\mathrm{B} 1$} & \multicolumn{3}{|c|}{ B2 } \\
\hline & \multirow{2}{*}{ Testlet } & \multicolumn{2}{|c|}{ Test Level 1} & \multirow{2}{*}{ Testlet } & \multicolumn{2}{|c|}{ Test Level 1} & \multicolumn{2}{|c|}{ Test Level 2} & \multirow{2}{*}{ Testlet } & \multicolumn{4}{|c|}{ Test Level 1 Test Level 2} & \multirow{2}{*}{ Testlet } & \multicolumn{2}{|c|}{ Test Level 3} \\
\hline & & P1 & $\mathrm{P} 2$ & & P3 & P4 & P1 & $\mathrm{P} 2$ & & P3 & P4 & P1 & $\mathrm{P} 2$ & & P1 P2 & P3 \\
\hline \multirow[t]{4}{*}{ English } & 1 & 71 & 71 & 4 & 40 & 40 & 66 & 67 & 8 & 55 & 56 & 81 & 80 & 11 & $64 \quad 63$ & 64 \\
\hline & 2 & 67 & 68 & 5 & 35 & 34 & 60 & 62 & 9 & 59 & 59 & 85 & & 12 & $68 \quad 68$ & 69 \\
\hline & 3 & 84 & 85 & 6 & 39 & 41 & 63 & 63 & 10 & 52 & 52 & & 79 & 13 & $52 \quad 55$ & 53 \\
\hline & & & & 7 & 64 & 65 & 82 & 82 & & & & & & & & \\
\hline \multirow[t]{4}{*}{ French } & 1 & 58 & 59 & 4 & 63 & 63 & 72 & 71 & 8 & 49 & 47 & 64 & 66 & 11 & $57 \quad 57$ & 56 \\
\hline & 2 & 65 & 64 & 5 & 51 & 53 & 65 & 63 & 9 & 54 & 54 & 68 & & 12 & $58 \quad 53$ & 53 \\
\hline & 3 & 56 & 59 & 6 & 56 & 55 & 63 & 61 & 10 & 34 & 33 & & 42 & 13 & $36 \quad 39$ & 39 \\
\hline & & & & 7 & 51 & 52 & 61 & 61 & & & & & & & & \\
\hline \multirow[t]{4}{*}{ German } & 1 & 62 & 61 & 4 & 43 & 43 & 53 & 53 & 8 & 50 & 51 & 68 & 69 & 11 & $55 \quad 50$ & 46 \\
\hline & 2 & 63 & 65 & 5 & 34 & 33 & 44 & 41 & 9 & 47 & 45 & 58 & & 12 & $56 \quad 58$ & 57 \\
\hline & 3 & 76 & 76 & 6 & 47 & 49 & 59 & 61 & 10 & 41 & 42 & & 60 & 13 & $43 \quad 42$ & 46 \\
\hline & & & & 7 & 61 & 59 & 70 & 71 & & & & & & & & \\
\hline \multirow[t]{4}{*}{ Spanish } & 1 & 55 & 57 & 4 & 47 & 48 & 54 & 56 & 8 & 43 & 41 & 53 & 57 & 11 & $34 \quad 34$ & 38 \\
\hline & 2 & 66 & 67 & 5 & 40 & 39 & 45 & 45 & 9 & 50 & 49 & 66 & & 12 & $34 \quad 38$ & 36 \\
\hline & 3 & 68 & 66 & 6 & 42 & 47 & 51 & 51 & 10 & 45 & 45 & & 61 & 13 & $22 \quad 22$ & 28 \\
\hline & & & & 7 & 53 & 53 & 60 & 58 & & & & & & & & \\
\hline
\end{tabular}

In the listening test, there is an overall tendency for the percentage of correct responses to increase as a function of position in every language. For example, in Spanish Testlet 3 increases from 56\% of correct responses in Position 1 to 64\% in Position 2, and 66\% in Position 3. This tendency is more evident in the testlets that represent the easier part of the test, namely A2 testlets for Test Level 2, and B1 testlets for Test Level 3. In reading, no overall tendency can be observed: the change in the percentage of correct responses varies greatly between testlets, CEFR levels, test levels, and languages. These results hint at possible practice effects in the listening assessment.

\section{Item position effects}

Table 8 shows the item position effects for all languages and tests. 
Table 8

Item position effects listening and reading for all languages

\begin{tabular}{|c|c|c|c|c|c|c|c|c|c|}
\hline \multirow{2}{*}{$\overline{\text { Listening }}$} & \multicolumn{5}{|c|}{ CEFR T. Level Position Cell Estimate } & \multirow{2}{*}{$\begin{array}{c}\text { English } \\
-0.14(0.02)\end{array}$} & \multirow{2}{*}{$\begin{array}{c}\text { French } \\
-0.06(0.03)\end{array}$} & \multirow{2}{*}{$\begin{array}{c}\text { German } \\
-0.11(0.03)\end{array}$} & \multirow{2}{*}{$\begin{array}{c}\text { Spanish } \\
-0.15(0.05)\end{array}$} \\
\hline & A2 & 2 & 2 & $\mathrm{D}_{l}$ & $\delta_{A 2_{2}}^{L 2}$ & & & & \\
\hline & $\mathrm{A} 2$ & 2 & 3 & $\mathrm{E}_{l}$ & $\delta_{A 2_{3}}^{L 2}$ & $-0.23(0.02)$ & $-0.10(0.03)$ & $-0.17(0.03)$ & $-0.17(0.05)$ \\
\hline & B1 & 2 & 5 & $\mathrm{G}_{l}$ & $\delta_{B 1_{5}}^{L 2}$ & $0.02(0.02)$ & $-0.03(0.03)$ & $0.05(0.03)$ & $-0.03(0.04)$ \\
\hline & B1 & 3 & 2 & $\mathrm{I}_{l}$ & $\delta_{B 1_{2}}^{L 3}$ & $-0.16(0.02)$ & $-0.01(0.04)$ & $-0.05(0.04)-$ & $-0.07(0.06)$ \\
\hline & B2 & 3 & 4 & $\mathrm{~K}_{l}$ & $\delta_{B 2_{4}}^{L 3}$ & $0.01(0.04)$ & $0.07)$ & $0.15(0.08)$ & $0.09(0.11)$ \\
\hline \multirow[t]{7}{*}{ Reading } & A1 & 1 & 2 & $\mathrm{~B}_{r}$ & $\delta_{A 1_{2}}^{L 1}$ & $-0.03(0.03)$ & -0.0 & -0.0 & $-0.03(0.07)$ \\
\hline & $\mathrm{A} 2$ & 1 & 4 & $\mathrm{D}_{r}$ & $\delta_{A 2_{4}}^{L 1}$ & $-0.02(0.02)$ & -0.0 & $0.00(0.03)-$ & $-0.06(0.06)$ \\
\hline & $\mathrm{A} 2$ & 2 & 2 & $\mathrm{~F}_{r}$ & $\delta_{A 2_{2}}^{L 2}$ & $-0.04(0.02)$ & $0.07(0.03)$ & $0.02(0.03)$ & $0.01(0.05)$ \\
\hline & B1 & 2 & 4 & $\mathrm{H}_{r}$ & $\delta_{B 1_{4}}^{L 2}$ & $0.00(0.02)$ & $0.09(0.04)$ & $0.02(0.03)$ & $0.06(0.05)$ \\
\hline & B1 & J & 2 & $\mathbf{J}_{r}$ & $\delta_{B 1_{2}}^{L 3}$ & $0.02(0.03)$ & $-0.11(0.05)$ & $0.00(0.04)$ & $0.03(0.07)$ \\
\hline & B2 & 3 & 2 & $\mathrm{~L}_{r}$ & $\delta_{B 2_{2}}^{L 3}$ & $-0.01(0.02)$ & $0.01(0.05)$ & $0.07(0.05)-$ & $-0.05(0.07)$ \\
\hline & B2 & 3 & 3 & $\mathbf{M}_{r}$ & $\delta_{B 2_{3}}^{L 3}$ & $-0.02(0.04)$ & $0.02(0.06)$ & $0.07(0.07)-$ & $-0.15(0.09)$ \\
\hline
\end{tabular}

Estimates with $p<0.05$ are shown in gray and italic font.

Both practice effects and fatigue effects were found across tests and languages. Consistent practice effects were found in the listening test for all languages, specifically for A2 items presented in Test Level 2. In reading, most of the item position effects were not statistically significant, and their direction varied between languages, CEFR levels, and test levels.

The larger practice effects in listening were found in English for A2 items in Test Level 2. For these items, if they were presented in Position 2, they had a negative impact on difficulty of -0.14 , which translates into a $4 \%$ increase of the probability of a correct response for an average student on an item with the difficulty parameter equal to ability, when these items were presented in Position 3 the impact on difficulty was -0.23 , which means a $6 \%$ increase of success probability.

\section{Differences between regions}

Further analyses were conducted to establish if the practice effects vary across regions. Previously found item position effects can become not statically significant or change their direction between regions. The results for all languages can be found in the Appendix. However, the practice effects varied between regions. These results confirmed the tendency of practice effects in listening, but also a mixture of practice and fatigue effects was found for some regions in reading. As an example Figure 2 shows the variation of the practice effects for A2 items for English listening, Figure 2 shows that although there is an overall tendency, practice effects 
can vary between regions. In East Belgium, if an A2 item is presented in Position 2, it will increase the probability of a correct response by $12 \%$ for an average student on an item of the same difficulty, but instead, it will only increase by $1 \%$ for an average Bulgarian student.

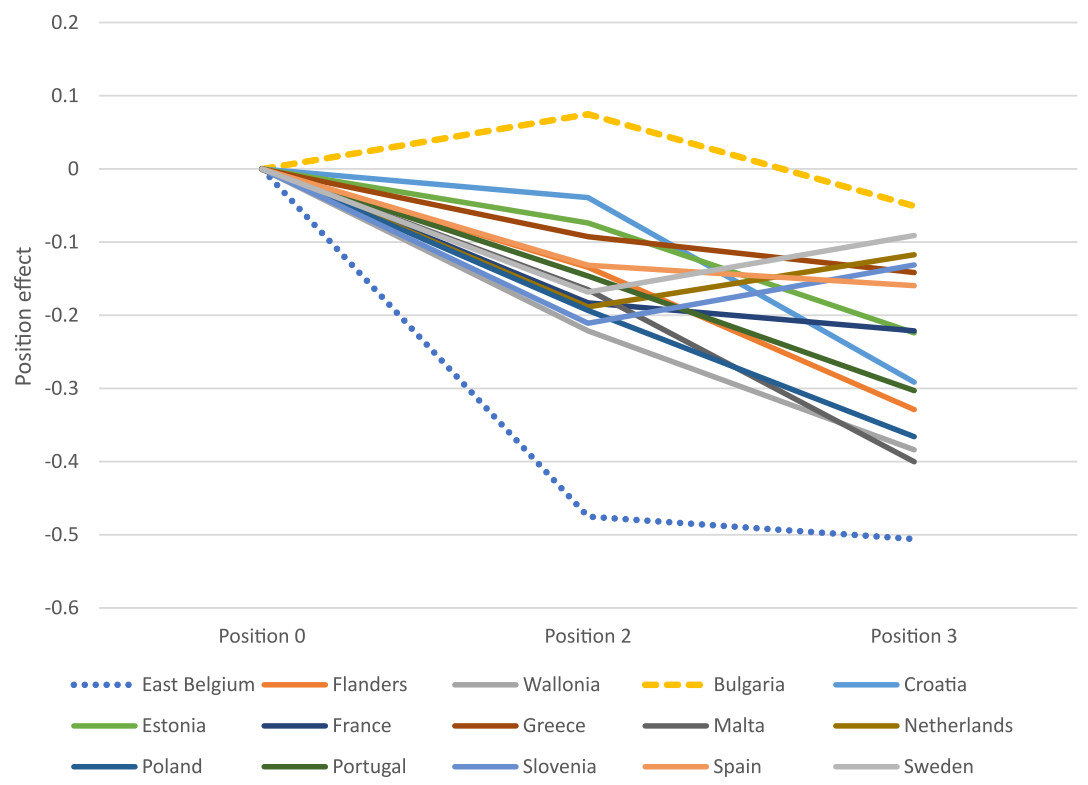

Figure 2. Item position effects per region - English listening - A2

The relationship between the region effects and the practice effects for listening was also analyzed. As shown in Figure 3, no relation was found between the region effects and the position effects for A2 and B1 items in Test Level 2 of English listening. Nevertheless, for B1 and B2 items in Test Level 3, lower performing regions present lower practice effects or even learning effects. On the contrary, higher performing regions show larger practice effects. 
(a)

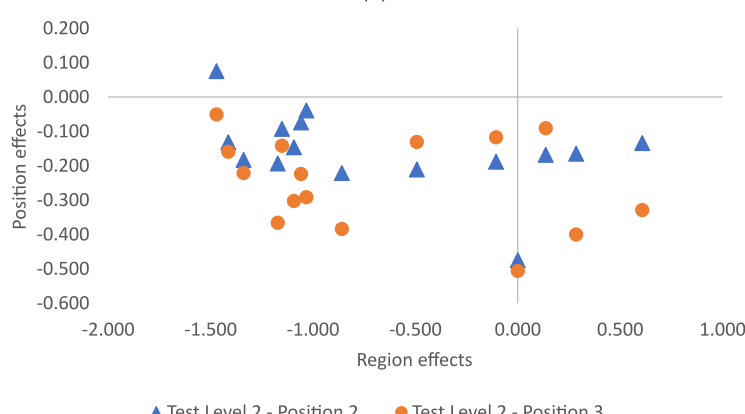

Test Level 2 - Position $2 \quad$ Test Level 2 - Position 3 (b)

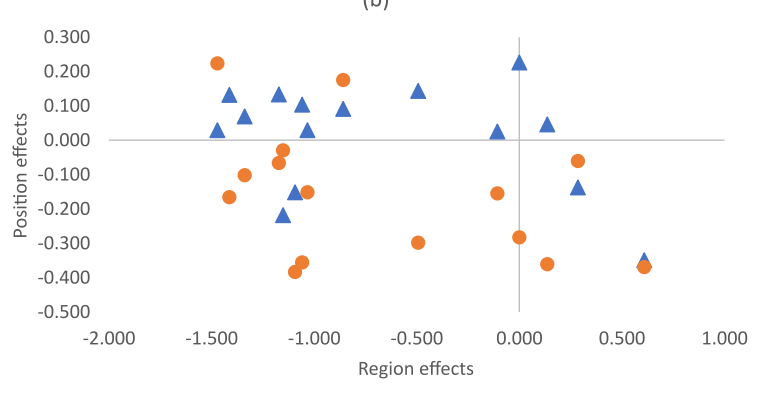

A Test Level 2 - Position $5 \quad$ Test Level 3 - Position 2

(c)

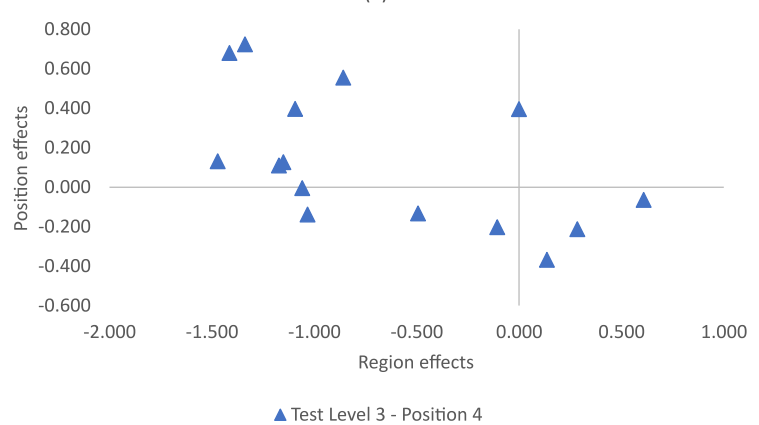

Figure 3. Scatterplots for region effects and position effects for (a) A2, (b) B1 and (c) B2 items of the English listening test.

Finally, since the form of administration varied by region between paper-based and computerbased, it was analyzed whether this could have influenced the position effects. No significant difference was found between the average position effects of both test modes.

\section{Discussion}

While international large-scale assessments are low-stakes for the participating students, they are usually considered high-stakes for educational policy-makers in at least some of the participating regions. Hence, it is of utmost importance that students' ability is estimated with a correct IRT model, which may not be the case when existing item position effects are not included in the measurement model. By using a DIF approach to detect item position effects (Debeer \& Janssen, 2013), the present study showed that in the ESLC survey, item position effects were present for listening comprehension, but not for reading comprehension across the different languages assessed. More specifically, it was found that especially for items assessing lower language levels item difficulty decreased when the item was presented later in the test. This practice effect differed between regions, but was not related to the test administration mode. As the practice effects were substantial, it seems advisable to include them in the measurement model. 
As previously mentioned, few educational measurement studies have been able to find practice effects; on the contrary, fatigue effects are commonly found throughout international largescale assessments. This finding may be particularly related to the characteristics of the listening competence. The decrease in difficulty as the test progresses, especially in items that are easier for students may be the result of an adaptive listening process. As M. H. Davis and Johnsrude (2003) point out, comprehension of spoken language is usually achieved without awareness. However, decoding difficult speech, in this case a non-native language, activates compensatory mechanisms, even involving different brain areas not used for everyday listening (see also Erb, Henry, Eisner, \& Obleser, 2013). Hence, successful speech comprehension depends on the conscious attention of the subject, which is capable of modulating the auditory process (Wild et al., 2012) and improves with the passage of time and repetition (Erb et al., 2013).

It is still to be investigated whether the found difference in item position effects between reading and listening may be generalized to other standardized language assessments, and if they endure over time. Nevertheless, the present study shows that it is worth investigating item position effects in large-scale assessments by using a test administration design that allows for their detection. When these effects are found in a calibration study, the item position effects can be taken into account in the measurement model and checked in the main study. Another approach when practice effects are found is to give students more time to adapt to the test and its recorded speech, e.g., by including unscored items at the beginning of the test. The latter may not always be a viable option given that large-scale assessments usually have limited testing time available for each individual.

In the present study, individual differences in the practice effect were not investigated as the design of test administration of the ESCL survey only had a limited number of points of comparison for checking item position effects. It would be interesting to find out whether test takers differ in the size of the practice effect or of their learning during the test and whether these individual differences covary with other student characteristics, as was found for gender for test persistence in the PISA assessments (Wu et al., 2019). One could say that when assuming as in the current study that every test taker is affected in the very same way, comparisons between groups of test takers are still valid. However, from a conceptual point of view, it is advisable to disentangle language ability from practice effect in order to have a better view of the construct validity of the test. 


\section{References}

Albano, A. D., Cai, L., Lease, E. M., \& McConnel, S. R. (2019). Computerized adaptive testing in early education: Exploring the impact of item position effects on ability estimation. Journal of Educational Measurement, 56(2), 437-451.

Bates, D., Mächler, M., Bolker, B., \& Walker, S. (2015). Fitting linear mixed-effects models using lme4. Journal of Statistical Software, 67(1), 1-48.

Bejar, I. I. (1985). Test seededness under number-right scoring: An analysis of the test of English as a foreign language (Report No. ETS-RR-85-11). Princeton, NJ: Educational Testing Service.

Bolt, D. M., Cohen, A., \& Wollack, J. (2002). Item parameter estimation under conditions of test speededness: Application of a mixture Rasch model with ordinal constraints. Journal of Educational Measurement, 39(4), 331-348.

Cosgrove, J., \& Cartwright, F. (2014). Changes in achievement on PISA: the case of Ireland and implications for international assessment practice. Large-scale Assessments in Education, 2(2).

Davis, J., \& Ferdous, A. (2005). Using item difficulty and item position to measure test fatigue. Paper presentation at the Annual Meeting of the American Educational Research Association, Montreal, Quebec.

Davis, M. H., \& Johnsrude, I. S. (2003). Hierarchical processing in spoken language comprehension. The Journal of Neuroscience, 23(8), 3423-3431.

Debeer, D., Buchholz, J., Hartig, J., \& Janssen, R. (2014). Student, school, and country differences in sustained test-taking effort in the 2009 PISA reading assessment. Journal of Educational and Behavioral Statistics, 39(6), 502-523.

Debeer, D., \& Janssen, R. (2013). Modeling item-position effects within an IRT framework. Journal of Educational Measurement, 50(2), 164-185.

De Boeck, P., Bakker, M., Zwitser, R., Nivard, M., Hofman, A., Tuerlinckx, F., \& Partchev, I. (2011). The estimation of item response models with the lmer function from the lme4 package in R. Journal of Statistical Software, 39(12).

De Boeck, P., \& Wilson, M. (2004). Explanatory item response models: A generalized linear and nonlinear approach. New York, NY: Springer.

Erb, J., Henry, M. J., Eisner, F., \& Obleser, J. (2013). The brain dynamics of rapid perceptual adaptation to adverse listening conditions. The Journal of Neuroscience, 33(26), 1068810697.

European Commission. (2012a). First European Survey on Language Competences: Final report. Brussels: Author.

European Commission. (2012b). First European Survey on Language Competences: Technical report. Brussels: Author.

Goegebeur, Y., De Boeck, P., Wollack, J., \& Cohen, A. (2008). A speeded item response model with gradual process change. Psychometrika, 73(1), 65-87.

Guertin, W. H. (1954). The effect of instructions and item order on the arithmetic subtest of the Wechsler-Bellevue. Journal of Genetic Psychology, 85(1), 79-83.

Hambleton, R. K., \& Traub, R. E. (1974). The effects of item order in test performance and stress. Journal of Experimental Education, 43(1), 40-46.

Hamilton, J. C., \& Shuminsky, T. R. (1990). Self-awareness mediates the relationship between serial position and item reliability. Journal of Personality and Social Psychology, 59(6), 1301-1037.

Hartig, J., \& Buchholz, J. (2012). A multilevel item response model for item position effects 
and individual persistence. Psychological Test and Assessment Modeling, 54(4), 418431.

Hohensinn, C., Kubinger, K. D., Reif, M., Holocher-Ertl, S., Khorramdel, L., \& Frebort, M. (2008). Examining item-position effects in large-scale assessment using the linear logistic test model. Psychology Science Quarterly, 50(3), 391-402.

Hohensinn, C., Kubinger, K. D., Reif, M., Schleicher, E., \& Khorramdel, L. (2011). Analysing item position effects due to test booklet design within large-scale assessment. Educational Research and Evaluation, 17(6), 497-509.

Jagodzinski, W., Kühnel, S. M., \& Schmidt, P. (1987). Is there a 'socratic effect' in nonexperimental panel studies. Sociological Methods and Research, 15(3), 259-302.

Kingston, N. M., \& Dorans, N. J. (1982). The effect of the position of an item within a test on item response behaviour: An analysis based on item response theory. GRE Board Professional Report GREB No. 79-12 bp ETS Research Report.

Kingston, N. M., \& Dorans, N. J. (1984). Item location effects and their implications for IRT equating and adaptive testing. Applied Psychological Measurement, 8(2), 147-154.

Knowles, E. S. (1988). Item context effects on personality scales: Measuring changes the measure. Journal of Personality and Social Psychology, 55(2), 312-320.

Knowles, E. S., \& Byers, B. (1996). Reliability shifts in measurement reactivity: Driven by content engagement or self-engagement? Journal of Personality and Social Psychology, 70(5), 1080-1090.

McGuire, W. J. (1960). Context and serial-order effects in personality measurement: Limits on the generality of measuring changes the measure. The Journal of Abnormal and Social Psychology, 60(3), 345-353.

Meyers, J. L., Miller, G. E., \& Way, W. D. (2009). Item position and item difficulty change in an IRT-based common item equating design. Applied Measurement in Education, 22(1), 38-60.

Nagy, G., Nagengast, B., Becker, M., Rose, N., \& Frey, A. (2018). Item position effects in a reading comprehension test: An IRT study of individual differences and individual correlates. Psychological Test and Assessment Modeling, 60(2), 165-187.

Nagy, G., Nagengast, B., Frey, A., Becker, M., \& Rose, N. (2018). A multilevel study of position effects in PISA achievement tests: student- and school-level predictors in the German tracked school system. Assessment in Education: Principles, Policy \& Practice, 26(4), 422-443.

Oshima, T. C. (1994). The effect of speededness on parameter estimation in item response theory. Journal of Educational Measurement, 31(3), 200-219.

R Core Team. (2019). R: A language and environment for statistical computing [Computer software manual]. Vienna, Austria.

Ren, X., Wang, T., Altmeyer, M., \& Schweizer, K. (2014). A learning-based account of fluid intelligence from the perspective of the position effect. Learning and Individual Differences, 31, 30-35.

Schweizer, K., Schreiner, M., \& Gold, A. (2009). The confirmatory investigation of APM items with loadings as a function of the position and easiness of items: A two-dimensional model of APM. Psychology Science, 51(1), 47-64.

Schweizer, K., Troche, S. J., \& Rammsayer, T. H. (2011). On the special relationship between fluid and general intelligence: New evidence obtained by considering the position effect. Personality and Individual Differences, 50, 1249-1254.

Steinberg, L. (1994). Context and serial-order effects in personality measurement: Limits on the generality of measuring changes the measure. Journal of Personality and Social 
Psychology, 66(2), 341-349.

Swinton, S. S., Wild, C. L., \& Wallmark, M. M. (1983). Investigation of practice effects on item types in the graduate record examinations aptitude test. Educational Testing Service.

Verguts, T., \& De Boeck, P. (2000). A Rasch model for detecting learning while solving an intelligence test. Applied Psychological Measurement, 24(2), 151-162.

Whitely, S. E., \& Dawis, R. V. (1976). The influence of test context on item difficulty. Educational and Psychological Measurement, 36, 329-337.

Wild, C. J., Yusuf, A., Wilson, D. E., Peelle, J. E., Davis, M. H., \& Johnsrude, I. S. (2012). Effortful listening: The processing of degraded speech depends critically on attention. The Journal of Neuroscience, 32(40), 14010-14021.

Wise, L. L. (1986). Latent trait models for partially speeded tests. Paper presented at the Annual Meeting of the American Educational Research Association, San Francisco.

Wu, Q., Debeer, D., Buchholz, J., Hartig, J., \& Janssen, R. (2019). Predictors of individual performance changes related to item positions in PISA assessments. Large-scale Assessments in Education, 7(5), 1-21.

Yamamoto, K., \& Everson, H. (1997). Modeling the effects of test length and test time on parameter estimation using the hybrid model. In J. Rost \& R. Langeheine (Eds.), Applications of latent trait and latent class models in the social sciences. New York: Waxmann.

Yen, W. M. (1980). The extent, causes and importance of context effects on item parameters for two latent trait models. Journal of Educational Measurement, 17(4), 297-311.

\section{Appendix}

Table 9

Region effects and item position effects per region - English

\begin{tabular}{|c|c|c|c|c|c|c|c|c|c|c|c|c|c|}
\hline \multirow{4}{*}{ Region } & \multirow{4}{*}{$\begin{array}{c}\text { Region } \\
\text { effect }\end{array}$} & \multicolumn{5}{|c|}{ Listening } & \multicolumn{7}{|c|}{ Reading } \\
\hline & & \multicolumn{3}{|c|}{ Test level 2} & \multicolumn{2}{|c|}{ Test level 3} & \multicolumn{2}{|c|}{ Test level 1} & \multicolumn{2}{|c|}{ Test level 2} & \multicolumn{3}{|c|}{ Test level 3} \\
\hline & & \multicolumn{2}{|c|}{$\mathrm{A} 2$} & \multicolumn{2}{|c|}{ B1 } & \multirow{2}{*}{\begin{tabular}{|c|} 
B2 \\
$\delta_{B 2{ }_{4}}^{L 3}$ \\
\end{tabular}} & \multirow{2}{*}{$\begin{array}{c}\mathrm{A} 1 \\
\delta_{A 1_{2}}^{L 1} \\
\end{array}$} & \multicolumn{2}{|c|}{$\mathrm{A} 2$} & \multicolumn{2}{|c|}{ B1 } & \multicolumn{2}{|c|}{ B2 } \\
\hline & & $\delta_{A 2_{2}}^{L 2}$ & $\delta_{A 22_{3}}^{L 2}$ & $\delta_{B 1_{5}}^{L 2}$ & $\delta_{B 1_{2}}^{L 3}$ & & & $\delta_{A 2_{4}}^{L 1}$ & $\delta_{A 2_{2}}^{L 2}$ & $\delta_{B 1_{4}}^{L 2}$ & $\delta_{B 1_{2}}^{L 3}$ & $\delta_{B 2_{2}}^{L 3}$ & $\delta_{B 2_{3}}^{L 3}$ \\
\hline (5) & & -0.48 & -0.51 & 0.23 & -0.28 & 0.40 & 0.07 & 0.30 & -0.12 & 0.13 & -0.17 & -0.01 & -0.07 \\
\hline landers & 0.61 & -0.13 & -0.33 & -0.35 & -0.37 & -0.06 & 0.38 & -0.48 & -0.09 & -0.31 & -0.22 & -0.07 & -0.08 \\
\hline Wallon & -0.86 & 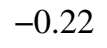 & -0.38 & 0.09 & 0.18 & 0.55 & -0.01 & 0.05 & -0.11 & -0.09 & -0.01 & -0.04 & -0.22 \\
\hline & & 07 & -0.05 & 0.03 & 0.22 & 0.13 & $0.2 J$ & 0.20 & 0.32 & 0.12 & -0.12 & -0.05 & -0.32 \\
\hline & .05 & -0.04 & -0.29 & 0.03 & -0.15 & -0.14 & -0.04 & -0.21 & -0.06 & -0.03 & 0.02 & 0.05 & -0.12 \\
\hline is & .06 & -0.07 & -0.22 & 0.10 & -0.36 & -0.01 & 0.05 & 0.10 & -0.17 & -0.05 & 0.19 & -0.10 & -0.05 \\
\hline & -1.34 & -0.18 & -0.22 & 0.07 & -0.10 & 0.72 & -0.21 & 0.08 & -0.02 & -0.14 & -0.03 & -0.32 & -0.19 \\
\hline & & -0.09 & -0.14 & -0.22 & -0.03 & 0.13 & -0.03 & -0.14 & -0.07 & -0.08 & -0 & -0.12 & 0.06 \\
\hline Malta & 0.29 & -0.17 & -0.40 & -0.14 & -0.06 & -0.21 & -0.07 & -0.38 & -0.18 & -0.08 & 0.35 & -0.01 & 0.24 \\
\hline & -0.11 & -0.19 & -0.12 & 0.03 & -0.15 & -0.20 & 0.35 & -0.21 & 0.01 & 0.07 & -0.04 & 0.06 & 0.08 \\
\hline & & -0.19 & -0.37 & & -0.07 & 0.11 & -0.03 & -0.03 & -0.21 & 0.13 & 0.21 & 0.07 & -0.10 \\
\hline & -1.09 & -0.15 & -0.30 & -0.15 & -0.38 & 0.40 & -0.07 & -0.02 & 0.06 & -0.07 & -0.12 & -0.07 & -0.27 \\
\hline & & -0.21 & -0.13 & 0.14 & -0.30 & -0.13 & 0.00 & -0.18 & -0.04 & 0.17 & 0.24 & 0.10 & 0.02 \\
\hline & -1.41 & -0.13 & -0.16 & 0.13 & -0.17 & 0.68 & -0.18 & 0.12 & -0.10 & 0.11 & -0.13 & -0.01 & 0.07 \\
\hline Sweden & 0.14 & -0.17 & -0.09 & 0.05 & -0.36 & -0.37 & 0.31 & 0.12 & -0.02 & 0.02 & 0.07 & 0.11 & 0.14 \\
\hline
\end{tabular}

Estimates with $p<0.05$ are shown in gray and italic font. 
Table 10

Region effects and item position effects per region - French

\begin{tabular}{|c|c|c|c|c|c|c|c|c|c|c|c|c|c|}
\hline \multirow{4}{*}{ Region } & \multirow{4}{*}{$\begin{array}{l}\text { Region } \\
\text { effect }\end{array}$} & \multicolumn{5}{|c|}{ Listening } & \multicolumn{7}{|c|}{ Reading } \\
\hline & & \multicolumn{3}{|c|}{ Test level 2} & \multicolumn{2}{|c|}{ Test level 3} & \multicolumn{2}{|c|}{ Test level 1} & \multicolumn{2}{|c|}{ Test level 2} & \multicolumn{3}{|c|}{ Test level 3} \\
\hline & & \multicolumn{2}{|c|}{$\mathrm{A} 2$} & \multicolumn{2}{|c|}{$\mathrm{B} 1$} & B2 & A1 & \multicolumn{2}{|c|}{$\mathrm{A} 2$} & \multicolumn{2}{|c|}{ B1 } & \multicolumn{2}{|c|}{ B2 } \\
\hline & & $\delta_{A 2_{2}}^{L 2}$ & $\delta_{A 2_{3}}^{L 2}$ & $\delta_{B 1_{5}}^{L 2}$ & $\delta_{B 1_{2}}^{L 3}$ & $\delta_{B 2_{4}}^{L 3}$ & $\delta_{A 1_{2}}^{L 1}$ & $\delta_{A 2_{4}}^{L 1}$ & $\delta_{A 2_{2}}^{L 2}$ & $\delta_{B 1_{4}}^{L 2}$ & $\delta_{B 1_{2}}^{L 3}$ & $\delta_{B 2_{2}}^{L 3}$ & $\delta_{B 2_{3}}^{L 3}$ \\
\hline East & .00 & -0.04 & -0.27 & 0.17 & 0.01 & 0.06 & -0.13 & 0.15 & 0.05 & 0.21 & -0.06 & 0.10 & 0.25 \\
\hline Fla & -0.32 & -0.05 & -0.25 & 0.05 & -0.08 & -0.02 & -0.17 & -0.26 & -0.03 & 0.17 & 0.00 & 0.02 & 0.09 \\
\hline Greece & -1.13 & -0.09 & 0.19 & -0.35 & 0.04 & 0.07 & 0.10 & -0.06 & 0.26 & 0.09 & -0.45 & 0.02 & 0.03 \\
\hline Portuga & -0.55 & -0.09 & -0.12 & -0.02 & 0.01 & -0.15 & 0.03 & -0.10 & 0.25 & -0.04 & -0.32 & -0.05 & -0.20 \\
\hline Spain & -0.57 & -0.04 & -0.11 & 0.03 & 0.00 & -0.31 & -0.11 & -0.03 & -0.12 & 0.08 & 0.09 & -0.09 & -0.16 \\
\hline
\end{tabular}

Estimates with $p<0.05$ are shown in gray and italic font.

Table 11

Region effects and item position effects per region - German

\begin{tabular}{|c|c|c|c|c|c|c|c|c|c|c|c|c|c|}
\hline \multirow{4}{*}{ Region } & \multirow{4}{*}{$\begin{array}{c}\text { Region } \\
\text { effect }\end{array}$} & \multicolumn{5}{|c|}{ Listening } & \multicolumn{7}{|c|}{ Reading } \\
\hline & & \multicolumn{3}{|c|}{ Test level 2} & \multicolumn{2}{|c|}{ Test level 3} & \multicolumn{2}{|c|}{ Test level 1} & \multicolumn{2}{|c|}{ Test level 2} & \multicolumn{3}{|c|}{ Test level 3} \\
\hline & & \multicolumn{2}{|c|}{$\mathrm{A} 2$} & \multicolumn{2}{|c|}{ B1 } & \multirow{2}{*}{$\begin{array}{c}\mathrm{B} 2 \\
\delta_{B 2_{4}}^{L 3} \\
\end{array}$} & \multirow{2}{*}{$\begin{array}{c}\mathrm{A} 1 \\
\delta_{A 1_{2}}^{L 1}\end{array}$} & \multicolumn{2}{|c|}{$\mathrm{A} 2$} & \multicolumn{2}{|c|}{ B1 } & \multicolumn{2}{|c|}{ B2 } \\
\hline & & $\delta_{A 2_{2}}^{L 2}$ & $\delta_{A 2_{3}}^{L 2}$ & $\delta_{B 1_{5}}^{L 2}$ & $\delta_{B 1_{2}}^{L 3}$ & & & $\delta_{A 2_{4}}^{L 1}$ & $\delta_{A 2_{2}}^{L 2}$ & $\delta_{B 1_{4}}^{L 2}$ & $\delta_{B 1_{2}}^{L 3}$ & $\delta_{B 2_{2}}^{L 3}$ & $\delta_{B 2_{3}}^{L 3}$ \\
\hline Wallonia & 0.00 & -0.28 & -0.31 & 0.09 & -0.15 & 0.12 & -0.20 & 0.00 & 0.03 & -0.11 & 0.12 & 0.22 & -0.04 \\
\hline Bulg & 54 & -0.09 & 0.06 & 0 & 0.18 & 0.40 & 0.05 & -0 & 0.17 & 0.04 & -0.03 & -0.10 & 0.01 \\
\hline Croatia & -0.43 & -0.08 & -0.25 & 0.01 & -0.09 & -0.28 & 0.15 & -0.06 & 0.07 & 0.04 & -0.06 & 0.01 & -0.05 \\
\hline Estonia & -0.25 & -0.19 & -0.23 & 0.18 & -0.16 & 0.06 & -0.13 & 0.01 & -0.09 & 0.09 & 0.18 & 0.19 & 0.14 \\
\hline ands & 1.04 & 0.02 & -0.26 & -0.04 & -0.48 & 0.13 & -0.23 & 0.14 & -0.07 & 0.00 & -0.06 & 0.07 & 0.06 \\
\hline Poland & -0.94 & 0.11 & 0.11 & -0.14 & 0.00 & 0.73 & -0.07 & -0.11 & 0.04 & -0.07 & -0.13 & 0.13 & -0.15 \\
\hline Slovenia & -0.06 & -0.30 & -0.32 & 0.25 & -0.05 & 0.06 & -0.07 & 0.16 & 0.00 & 0.09 & 0.00 & 0.18 & 0.32 \\
\hline
\end{tabular}

Estimates with $p<0.05$ are shown in gray and italic font.

Table 12

Region effects and item position effects per region - Spanish

\begin{tabular}{|c|c|c|c|c|c|c|c|c|c|c|c|c|c|}
\hline \multirow{4}{*}{ Region } & \multirow{4}{*}{$\begin{array}{l}\text { Region } \\
\text { effect }\end{array}$} & \multicolumn{5}{|c|}{ Listening } & \multicolumn{7}{|c|}{ Reading } \\
\hline & & \multicolumn{3}{|c|}{ Test level 2} & \multicolumn{2}{|c|}{ Test level 3} & \multicolumn{2}{|c|}{ Test level 1} & \multicolumn{2}{|c|}{ Test level 2} & \multicolumn{3}{|c|}{ Test level 3} \\
\hline & & \multicolumn{2}{|c|}{$\mathrm{A} 2$} & \multicolumn{2}{|c|}{ B1 } & B2 & A1 & \multicolumn{2}{|c|}{ A2 } & \multicolumn{2}{|c|}{ B1 } & \multicolumn{2}{|c|}{ B2 } \\
\hline & & $\delta_{A 2_{2}}^{L 2}$ & $\delta_{A 2_{3}}^{L 2}$ & $\delta_{B 1_{5}}^{L 2}$ & $\delta_{B 1_{2}}^{L 3}$ & $\delta_{B 2_{4}}^{L 3}$ & $\delta_{A 1_{2}}^{L 1}$ & $\delta_{A 2_{4}}^{L 1}$ & $\delta_{A 2_{2}}^{L 2}$ & $\delta_{B 1_{4}}^{L 2}$ & $\delta_{B 1_{2}}^{L 3}$ & $\delta_{B 2_{2}}^{L 3}$ & $\delta_{B 2_{3}}^{L 3}$ \\
\hline nn & 00 & -0.21 & -0.26 & 0.05 & -0.16 & 0.25 & 0.09 & -0.03 & 0.02 & 0.10 & 0.12 & 0.03 & -0.08 \\
\hline weden & -0.37 & -0.10 & -0.09 & -0.11 & 0.09 & -0.23 & -0.14 & -0.09 & 0.00 & 0.03 & -0.07 & -0.19 & -0.29 \\
\hline
\end{tabular}

Estimates with $p<0.05$ are shown in gray and italic font. 